\title{
Aetiological spectrum, injury characteristics and treatment outcome of multiple injuries at a tertiary care hospital in Tanzania
}

\author{
ABDUL ISSA 1 , NKINDA MBELENGE², PHILLIPO L. CHALYA ${ }^{1 *}$ and JAPHET M. GILYOMA ${ }^{3}$ \\ ${ }^{1}$ Department of Surgery, Catholic University of Health and Allied Sciences-Bugando, Mwanza, Tanzania \\ ${ }^{2}$ Department of Orthopaedics/Trauma, Catholic University of Health and Allied Sciences-Bugando, Mwanza, Tanzania \\ ${ }^{3}$ Department of Otorhinolaryngology, Catholic University of Health and Allied Sciences-Bugando, Mwanza, Tanzania
}

\begin{abstract}
Background: Multiple injuries constitute a public health problem and contribute significantly to high morbidity, mortality and long-term disabilities worldwide. This study describes the etiological spectrum, injury characteristics and treatment outcome of multiple injuries at a tertiary care hospital in Tanzania.

Methods: This was a descriptive prospective study involving multiple injury patients admitted to Bugando Medical Centre (BMC) from March 2013 to June 2013 inclusive.

Results: Out of 712 trauma patients who were admitted to BMC during the study period, 150 (21.1\%) had multiple injuries. Their male to female ratio was of 2.3:1. The majority of patients were in the second decade of life. Road traffic accidents (RTAs) were the most common (93.3\%) cause of injury. The majority of patients, $142(94.7 \%)$ sustained blunt injuries. Twelve (8.0\%) patients had pre-hospital care. The limbs (89.2\%) and the head (78.7\%) were the most common body regions injured. The majority of patients $(85.3 \%)$ sustained severe injuries (ISS $\geq 16)$. Out of 150 patients, $46(30.7 \%)$ had 65 missed injuries. A total of $142(94.7 \%)$ patients were treated surgically. Wound debridement (87.3\%) was the most common surgical procedure performed. The complication and mortality rates were $54.7 \%$ and $38.7 \%$, respectively. The overall median length of hospital stay (LOS) was 23 days. Co-morbid illness, HIV positivity, CD4 count $(\leq 200$ cells $/ \mu \mathrm{l})$, severe trauma (ISS $\geq 16)$, admission Systolic Blood Pressure $<90$ $\mathrm{mmHg}$, missed injuries and surgical site infection significantly influenced mortality $(P<0.001)$. Patients who developed complications and those who had long bone fractures stayed longer in the hospital $(p<0.001)$.

Conclusion: Road traffic accidents remain a major cause of multiple injuries at BMC and contribute significantly to unacceptably high morbidity and mortality. Urgent preventive measures targeting at reducing the occurrence of road traffic accidents is necessary to reduce the incidence of multiple injuries in our centre.
\end{abstract}

Keywords: multiple injuries, etiological spectrum, injury characteristics, treatment outcome, Tanzania

\section{Introduction}

Multiple injuries, defined as injuries to two or more systems, even in the same body region, constitute a global public health problem and contribute significantly to high morbidity, mortality and long-term disabilities worldwide (Park, 2000; Hofman et al., 2005\}.These injuries are associated with greater severity, worse outcomes, and usually require treatment by a multidisciplinary team of physicians because of the involvement of several body regions or numerous injury natures (Park, 2000). Multiple injuries are often life threatening and usually present as an emergency, requiring either immediate surgical intervention or intensive care or both (Moini, 2000).

In low-income countries including Tanzania, injuries in general are increasing due to increase in urbanization, motorization, civil violence, wars and criminal activities (Museru \& Leshabari, 2002; Bevan et al., 2008; Chalya et al., 2010). In these countries, multiple injuries remain a major cause of hospitalization and intensive care utilization and consume a significant amount of the health care budget (Bevan et al., 2008). In Bugando Medical Centre, multiple injuries are the single most common reason for admission to the Intensive Care Unit and are associated with substantial emotional, physical and financial burden on

\footnotetext{
*Correspondence Email: plchalya65@gmail.com
} 
community and hospital resources (Chalya et al., 2011). With observed rapid motorization (e.g. commercial motorcycles) and other factors such as civil violence and criminal activities in Mwanza city, the hospital has witnessed a significant increase in the number of trauma admissions, the majority of patients being severely and multiply injured (Chalya et al., 2010, 2011, 2012; Chalya \& Gilyoma, 2012). Multiple injuries remain a major cause of hospitalization and intensive care utilization in our setting (Chalya et al., 2011).

The management of multiple trauma patients presents a worldwide diagnostic and therapeutic challenge to trauma, orthopaedic and general surgeons (Park, 2000; Mitchell et al., 2001; Hofman et al., 2005; Abubakar et al., 2008). Significant injuries can be missed during primary and secondary surveys in multiply injured patients, for whom resuscitation, diagnosis and therapy have to proceed simultaneously (Enderson \& Maull, 1991; Mitchell et al., 2001; Brooks et al., 2004; Chalya et al., 2010). Many factors involved in the initial resuscitation of the multiple trauma patients, such as altered level of consciousness, hemodynamic instability, or inexperience and inadequate diagnostic evaluation, may lead to missed injuries (Shirzard et al., 2002; Chalya et al., 2010). Missed injuries are often associated with prolonged length of hospital stay resulting in increased costs of care as well as consumption of hospital resources (Shirzard et al., 2002; Kalemoglu et al., 2006; Sandra et al., 2008; Duane et al., 2008; Chalya et al., 2010). The challenge is even more conspicuous in countries where there is limited resources for caring of these patients coupled with lack of advanced pre-hospital and ineffective ambulance systems (Museru \&Leshabari, 2002; Chalya et al., 2010, 2011, 2012; Chalya \& Gilyoma., 2012).

Despite continued advances in intensive care unit technology and the availability of sophisticated interventions for the treatment of critically ill or severely injured patients (Moini, 2000; Duane et al., 2008), the outcome of multiple injury patients has not improved much in our setting. The reason for this state of affairs is not known probably because of lack of local data. This study is intended to bridge the existing knowledge gap on this subject and help identify factors responsible for the poor outcome among these patients. Identification of factors responsible for this state of affairs is of paramount importance in order to improve the outcome of the patients. This study describes our experiences on the management of multiple injuries outlining their etiological pattern, injury characteristics and treatment outcomes and identifies factors that predict the treatment outcomes at Bugando Medical Centre, a tertiary care hospital in north-western Tanzania.

\section{Materials and Methods}

\section{Study design and setting}

This was a descriptive prospective study involving multiple injury patients admitted to Bugando Medical Centre (BMC) from March 2013 to May 2013 inclusive. BMC is one of the four largest referral hospitals in the country and it is located in Mwanza city in the north-western part of Tanzania. It has a bed capacity of 890 and serves as a referral centre for tertiary specialist care for a catchment population of approximately 13 million people from north-western Tanzania. It is also a consultant and teaching hospital for the Catholic University of Health and Allied Sciences-Bugando (CUHAS-Bugando) and other paramedics. The hospital has a well-designed and modern Accident and Emergency (A\&E) department which receive and provide care for all critically ill and severely injured patients including multiple injured patients. In addition the hospital has a 12-bed adult and 10-bed paediatric multi-disciplinary Intensive Care Unit (ICU). The ICU provides services to all patients (trauma and non-trauma, medical and surgical) requiring advanced airway support, mechanical ventilation, hemodynamic support, and electronic monitoring. The majority of trauma patients admitted in the ICU come from the A \& E department, operating theatre, wards and others come from other peripheral hospitals. 


\section{Study population}

The study population included all multiple injury patients of all age groups and sex presenting to the $A \& E$ department, ICU and surgical wards of BMC. All multiple injury patients of any age group and genders and those who consented for the study and HIV testing were included. Unconscious patients without next of kin to consent and give information and those who died before complete assessment were excluded from the study. In this study, unconscious patients who gained consciousness later and be able to consent for the study and give information were included in the study. Patients refusing treatment modalities e.g. limb amputation and those who refused HIV testing were also excluded from the study. Multiple injuries was defined as injuries to two or more systems, even in the same body region. The minimum sample size was estimated using Kish and Lisle formula (1965). Convenience sampling of patients who meet the inclusion criteria were performed until the sample size was reached.

Recruitment of patient to participate in the study was done at the A\&E department and ICU after primary and secondary surveys done by the admitting surgical team. Patients were screened for inclusion criteria and those who met the inclusion criteria were offered explanations about the study and requested to consent before being enrolled into the study. In addition, all patients were requested to test for HIV infection. All patients were pre-counselled by a professional HIV counsellor according to current guidelines in the hospital. The patients were offered to be informed of the result of the HIV test. Relevant information regarding the history, physical examination, treatment modalities and outcome measures was documented.

All recruited patients were initially be resuscitated according to advanced trauma life support (ATLS). The severity of injury was determined using the injury severity score (ISS) (Chawda et al., 2004). Patients with head injuries were classified according to Glasgow Coma Scale (GCS) into: severe (GCS 3-8), moderate (GCS 9-12) and mild (GCS 13-15). An initial systolic blood pressure (SBP) on each patient was also recorded on admission. Routine laboratory investigations including haematological (haemoglobin, blood grouping haematocrit levels), biochemical (serum creatinine, serum electrolytes), serology (HIV testing) was taken to all patients. HIV serology test was performed using the Tanzania HIV Rapid Test Algorithm (Lyamuya et al., 2009). CD4+ cell count was performed using FACS Count or FACSCALIBUR (BD Biosciences USA), to all HIV positive patients to determine the degree of immunosuppression. Imaging studies like $x$-rays, ultrasound and Computer Tomography were also taken depending on the type of injury. Depending on the type of injury, the patients were treated either conservatively or by surgery. Patients were followed up till discharge or death. The length of hospital stay and mortality as measures of outcome of multiple injury patients were recorded at the end of the study. HIV positive patients were referred to the Care and Treatment Clinic (CTC) after post-counselling. Details of demographic profile, pre-morbid illness, causes of injury, injury characteristics, injury severity using Glasgow Coma scale (GCS), injury severity score (ISS), HIV status/ CD 4+ count levels, treatment offered, blood transfusion requirement, treatment complications, length of stay (LOS), mortality and patient disposal were documented.

\section{Data analysis}

Data analysis was done using SPSS software (Statistical Package for the Social Sciences, version 17.0, SPSS Inc, Chicago, III, USA). The median + Interquartile Range (IQR) and ranges were calculated for continuous variables whereas proportions and frequency tables were used to summarize categorical variables. Chisquare $\left(\chi_{2}\right)$ test were used to test for the significance of association between the independent (predictor) and dependent (outcome) variables in the categorical variables. The level of significance was considered as $p<0.05$. Study variables that were found to be statistically significant in univariate analysis 
were subjected to multivariate logistic regression analysis. Multivariate logistic regression analysis was used to determine predictor variables that predict the postoperative complications, hospital stay and mortality.

\section{Ethical considerations}

The study was carried out after the approval by BMC/CUHAS-Bugando ethics review board. An informed written consent was sought from patients or relatives.

\section{Results}

\section{Patient's characteristics}

During the study period, a total of 712 trauma patients were managed at BMC. Of these, 159 patients had multiply injuries and were eligible for the study. Out of 159 patients, nine were excluded from the study due to failure to meet the inclusion criteria. Thus, 150 patients representing $21.1 \%$ of all trauma admissions during the study period were enrolled into the study. Out of 150 patients, 104 (69.3\%) were males and 46 (30.7\%) were females with males out-numbering females by a ratio of 2.3:1. The age of patients at presentation ranged from 5 to 78 years with a median age of 26 years (interquartile range, 23 to 34 years). The age peak incidence was $21-30$ years accounting for $56.0 \%$ of cases (Figure 1). One hundred and twenty-one ( $80.7 \%)$ patients were aged 40 years and below.

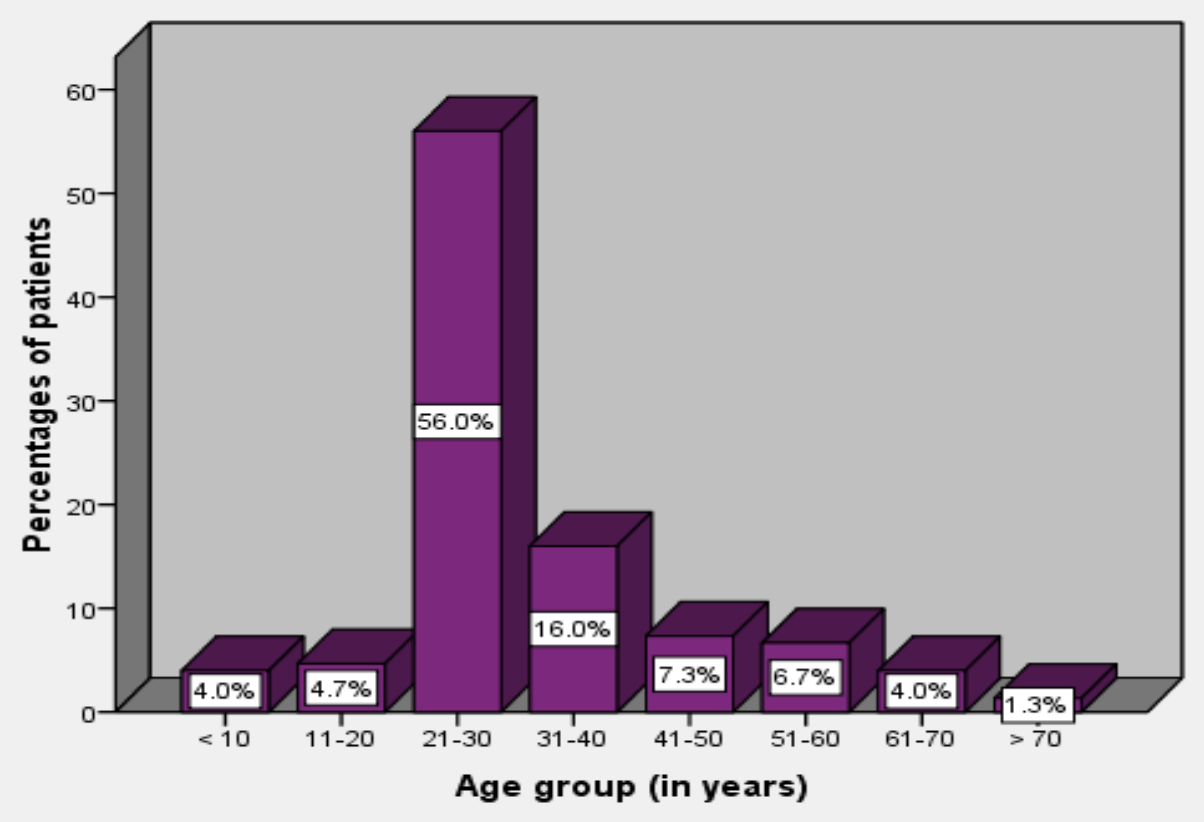

Figure 1: Distribution of patients according to age group

The majority $(54.0 \%)$ of patients had primary school education and most of them, $82(54.7 \%)$ were unemployed and the remaining $68(45.3 \%)$ patients were public servants, students, small scale businessmen and farmers. Of the 150 patients, 92 (61.3\%) came from the low-income urban areas (high 
density areas) of Mwanza city and the remaining 38.7\% came from rural areas located a considerable distance from the study area.

Twelve (8.8\%) patients reported to have pre-morbid illness. These included diabetes mellitus in 4 (33.3\%), hypertension in $3(25.0 \%)$, renal disease in $2(16.7 \%)$ and pulmonary tuberculosis $2(16.7 \%)$ and congenital heart disease in $1(8.3 \%)$ patient. Out of 150 patients, $16(10.7 \%)$ were HIV positive. Of these, $2(\%)$ were known cases on anti-retroviral therapy (ARV) and the remaining 14 (87.5\%) patients were newly diagnosed patients. Out of 16 patients with HIV, 12(75.0\%) were found to have risk factors for HIV infection. Of these, multiple sexual partners (Odd Ratio 4.32, C.I. (1.32 6.46), p = 0.023) and alcoholism (Odd Ratio 3.14, C.I. (2.67-12.09), $p=0.011$ ) were found to be independently and significantly associated with increased risk to HIV infection. Their CD4 count ranged from 123 to 746 cells/ $\mu$ l (mean $=463 \pm 122$ cells $/ \mu \mathrm{l})$. Six $(37.5 \%)$ of the HIV-infected patients had CD4 count $\leq 200$ cells/ $\mu \mathrm{l}$ and the remaining ten (62.5\%) had CD4 count $>200$ cells $/ / \mu$ l.

\section{Circumstances of the injury}

Regarding the time of the accident, 114(76.0\%) accidents occurred during the day and 36(24.0\%) at night. Road traffic accidents (RTAs) were the most common cause of injury accounting for 140 (93.3\%) patients. Ninety-eight (65.3\%) of RTAs were related to motorcycle injuries affecting motorcyclists (54, 55.1\%), passengers $(34,34.7 \%)$ and pedestrians $(10,10.2 \%)$. Helmet use and seat belt use among motorcyclists and occupants of vehicles were recorded in $38.8 \%$ (38/98) and 28.6\% (12/42) of patients, respectively. History of alcohol consumption prior to the accident was reported in 59 (39.3\%) patients. Other causes of injury included assaults in $5(3.3 \%)$ patients, fall from a height, and animal attack in $2(1.3 \%)$ patients each respectively; and gunshot in $1(0.7 \%)$ patient. The road was the most common place of injury in $140(93.3 \%)$ patients, followed by home, recreational and working places in $5(3.3 \%), 3(2.0 \%)$ and $2(1.4 \%)$ patients, respectively.

A total of $142(94.7 \%)$ injuries were unintentional. Intentional injuries occurred in $6(4.0 \%)$ patients mainly due to physical violence. The remaining $2(1.4 \%)$ patients were cases of undetermined intent. The vast majority of patients, $142(94.7 \%)$ sustained blunt injuries and the remaining $8(5.3 \%)$ had penetrating injuries. The blunt to penetrating injuries ratio was 17.8: 1.

Table 1: Distribution of patients according to body region injured $(\mathrm{N}=150)$

\begin{tabular}{lll}
\hline Body region injured & Frequency & Percentages \\
\hline Limbs (extremities) & 134 & 89.3 \\
Head/neck & 118 & 78.7 \\
Chest & 104 & 69.3 \\
Abdomen & 98 & 65.3 \\
Pelvis & 21 & 14.0 \\
Spines & 14 & 9.3 \\
\hline
\end{tabular}

Note: one patient sustained injury to more than one body region

In this study, only twelve (8.0\%) patients had pre-hospital care. The majority of patients were brought in by relatives or Good Samaritans in 118 (78.7\%) patients. Twenty-eight (18.7\%) patients were brought in by police and four (2.7\%) patients were brought in by ambulance. Regarding mode of transport, 117(78.0\%) patients were brought in by public transport, $28(18.7 \%)$ by police vehicle, $4(2.7 \%)$ by ambulance and 1 (0.7\%) patient by a three-wheel motorcycle. The majority of patients, $78(52.0 \%)$ arrived at the hospital between 1 hour and 6 hours. The remaining 23 (15.3\%) patients arrived in less than 1 hour, 20 (13.3\%) between 6 and 24 hours, $17(11.3 \%)$ and $12(8.0 \%)$ in more than 48 hours. The waiting time, defined as the time interval taken from reception at the A \& E department and reception of treatment ranged from 15 
minutes to 8 hours with a median of 3 hours (Interquartile range, 2 to 5 hours). The majority of patients, 82 (54.7\%) were attended to within 4 hours of arrival to the A \& E department. 


\section{Injury characteristics}

All patients (100\%) in this study sustained multiple injuries. The limbs (extremities) and the head were the most common body regions injured accounting for $89.2 \%$ and $78.7 \%$ of cases, respectively (Table 1). Open wounds (i.e. bruises, abrasions, lacerations, crush wounds, traumatic amputation, etc.) and fractures were the most common type of injuries sustained (Table 2).

Table 2: Distribution of patients according to the type of injury

\begin{tabular}{lll}
\hline Type of injury & Frequency & Percentage \\
\hline Open wounds & 132 & 88.0 \\
Fractures & 120 & 80.0 \\
- Lower limb fractures & 31 & 20.7 \\
- Upper limb fractures & 25 & 16.6 \\
- Skull/maxillofacial/neck fractures & 22 & 14.7 \\
- Rib fractures & 18 & 12.0 \\
- Pelvic fractures & 16 & 10.7 \\
- Spinal fractures & 8 & 5.3 \\
Intracranial haemorrhages & 118 & 78.7 \\
- Subdural & 34 & 22.7 \\
- Epidural & 32 & 21.3 \\
- Subarachnoid & 30 & 20.0 \\
- Intracerebral & 22 & 14.7 \\
Visceral injuries & 98 & 65.3 \\
- Spleen & 46 & 30.7 \\
- Bowels & 24 & 16.0 \\
- Liver & 16 & 10.7 \\
- Urinary bladder & 8 & 5.3 \\
- Urethra & 4 & 2.7 \\
Traumatic amputation & 45 & 30.0 \\
Pneumothorax & 42 & 28.0 \\
Haemothorax & 13 & 8.7 \\
Other injuries & 18 & 12.0 \\
\hline
\end{tabular}

Injury Severity Score (ISS) performed in all patients revealed that the majority of patients, 128 (85.3\%) had severe injuries whereas the remaining $22(14.7 \%)$ had moderate injuries. No patient had mild injuries. The Glasgow coma scale in patients with head injuries indicated that most of them, 118 (78.7\%) had moderate to severe injuries. A total of $78(52.0 \%)$ patients had systolic blood pressure (SBP) $>90 \mathrm{mmHg}$ on admission and the remaining 72(48.0\%) patients had SBP of 90mmHg and below.

Out of 150 patients, $46(30.7 \%)$ patients had 65 missed injuries. The most frequent missed injuries involved the head/neck $(n=26 ; 40.0 \%)$ and abdominal regions $(n=22 ; 33.8 \%)$. The remaining $17(26.2 \%)$ missed injuries involved other parts of the body. Clinical error due to incomplete clinical assessment during primary and secondary survey phases was the most common factor contributed to the occurrence of missed injuries and accounted for $69.2 \%$ (45/65) of all missed injuries. Table 3 shows a comparison of patient's characteristics and outcome among patients with and without missed injuries. 
Table 3: Comparison of patients 'characteristics and outcome among multiple injury patients with or without missed injuries

\begin{tabular}{llll}
\hline Study variables & Missed injuries & No missed injuries & $p$-value \\
\hline Number of patients & 65 & 85 & \\
Mean age (in years) + Standard deviation & $32.2 \pm 12.6$ & $28.8 \pm 10.2$ & NS \\
Sex (M:F ratio) & $2.2: 1$ & $2.0: 1$ & NS \\
Median ISS & 36 & 18 & 0.001 \\
Median GCS & 8 & 12 & 0.012 \\
Need for additional surgery (N/\%) & $18(27.7)$ & $12(14.1)$ & 0.003 \\
Mortality rate (N/\%) & $38(58.5)$ & $20(23.5)$ & 0.001 \\
\hline
\end{tabular}

Keys: $\mathrm{M}: \mathrm{F}=$ male to female, ISS =Injury severity score, GCS= Glasgow score

\section{Admission patterns and treatment modalities}

The majority of patients, 104 (69.3\%) were admitted in the general and orthopaedic surgical wards and the remaining 46 (30.7\%) in the Intensive Care Unit (ICU). Of those who were admitted in the ICU, 44 (95.7\%) patients needed ventilatory support. A total of $142(94.7 \%)$ patients were treated surgically. Wound debridement was the most common surgical procedure performed in $87.3 \%$ of patients (Table 4 ).

Table 4: Distribution of patients according to the surgical procedure performed $(\mathrm{N}=142)$

\begin{tabular}{lll}
\hline Surgical procedure performed & Number of patients & Percentage \\
\hline Wound debridement & 124 & 87.3 \\
Treatment of fractures & 76 & 53.6 \\
Craniotomy / bur holes & 72 & 50.7 \\
Exploratory laparotomy & 70 & 49.3 \\
Underwater seal drainage & 34 & 38.0 \\
Limb amputation & 32 & 22.5 \\
Other surgical procedures & 18 & 12.7 \\
\hline
\end{tabular}

\section{Treatment outcomes}

A total of 98 complications were recorded in 82 patients giving a complication rate of $54.7 \%$. Of these, surgical site infection was the most common complication accounting for $45.9 \%$ of cases (Table 5 ).

Table 5: Distribution of patients according to complications $(\mathrm{N}=98)$

\begin{tabular}{lll}
\hline Complications & Frequency & Percentage \\
\hline Surgical site infection & 45 & 45.9 \\
Complication of fractures & 23 & 23.5 \\
Complications of abdominal surgery & 14 & 14.3 \\
Haemorrhagic / septic shock & 12 & 12.2 \\
Tetanus & 8 & 8.2 \\
Subcutaneous emphysema & 6 & 6.1 \\
Empyema thoracis & 4 & 4.1 \\
\hline
\end{tabular}

The overall LOS ranged from 1 day to 124 days with a median of 23 days + (IQR=14 to 33 days). LOS for non-survivors ranged from 1 day to 12 days with a median of 4 days $+(I Q R=3$ to 6 days). The length of ICU 
stay ranged from 1 day to 43 days with a median of .days $+(I Q R=3$ to 12 days). According to multivariate logistic regression analysis, patients who developed complications and those who had long bone fractures stayed longer in the hospital and this was significant $(p<0.001)$. A total of 58 patients died giving a mortality rate of $38.7 \%$. Table 6 shows predictors of mortality according to univariate and multivariate analysis.

Table 6: Predictors of mortality according to univariate and multivariate analysis

\begin{tabular}{|c|c|c|c|c|c|c|}
\hline \multirow[t]{2}{*}{ Predictor Variable } & \multirow{2}{*}{$\begin{array}{l}\text { No. of } \\
\text { Alive }(n=92)\end{array}$} & \multirow{2}{*}{$\begin{array}{l}\text { Patients } \\
\text { Died }(n=58)\end{array}$} & \multirow{2}{*}{$\begin{array}{l}\text { Univariate analysis } \\
\text { OR }(95 \% \mathrm{Cl})\end{array}$} & \multirow[b]{2}{*}{$\mathbf{P}$} & \multicolumn{2}{|c|}{ Multivariate analysis } \\
\hline & & & & & OR (95 \% Cl) & $\mathbf{p}$ \\
\hline \multicolumn{7}{|l|}{ Age } \\
\hline - $\leq 40$ & $75(62.0)$ & $46(38.0)$ & 1 & & & \\
\hline - $\quad>40$ & $17(58.7)$ & $12(41.3)$ & $0.3(0.1-1,80$ & 0.213 & & \\
\hline \multicolumn{7}{|l|}{ Sex } \\
\hline - Male & $64(61.5)$ & $40(38.5)$ & 1 & & & \\
\hline - Female & $28(60.9)$ & $18(39.1)$ & $0.4(0.2-5.4)$ & 0.983 & & \\
\hline \multicolumn{7}{|l|}{ Pre-morbid illness } \\
\hline - Yes & $4(33.3)$ & $8(66.7)$ & 1 & & 1 & \\
\hline - $\quad$ No & $88(63.8)$ & $50(36.2)$ & $2.3(1.2-4.6)$ & 0.002 & $4.7(2.1-7.9)$ & 0.011 \\
\hline \multicolumn{7}{|l|}{ HIV status } \\
\hline - Positive & $6(37.5)$ & $10(62.5)$ & 1 & & 1 & \\
\hline - $\quad$ Negative & $86(64.2)$ & $48(35.8)$ & $3.8(2.9-7.1)$ & 0.033 & $4.0(2.8-8.2)$ & 0.021 \\
\hline \multicolumn{7}{|l|}{ CD4+count } \\
\hline - $\leq 200$ & $2(33 \cdot 3)$ & $4(66.7$ & 1 & & 1 & \\
\hline - $\quad>200$ & $10(80.0)$ & $2(20.0)$ & $5.4(2.1-8.9)$ & 0.003 & $3.8(2.2-8.9)$ & 0.000 \\
\hline \multicolumn{7}{|l|}{ Mechanism of injury } \\
\hline - Blunt & $87(61.3)$ & $55(38.7)$ & 1 & & & \\
\hline - Penetrating & $5(62.5)$ & $3(37.5)$ & $0.6(0.4-1.9)$ & 0.964 & & \\
\hline \multicolumn{7}{|l|}{$\begin{array}{l}\text { Injury-arrival time } \\
\text { (hours) }\end{array}$} \\
\hline - $\quad \leq 24$ & $81(66.9)$ & $40(33.1)$ & 1 & & 1 & \\
\hline - $\quad>245$ & $11(37.9)$ & $18(62.1)$ & $3.6(2.2-10.3)$ & 0.006 & $1.8(1.3-6.9)$ & 0.001 \\
\hline \multicolumn{7}{|l|}{ Admission SBP (mmHg) } \\
\hline - $\quad \leq 90$ & $32(44.4)$ & $40(55.6)$ & 1 & & 1 & \\
\hline - $\quad>90$ & $60(76.9)$ & $18(23.1)$ & $0.2(0.1-0.9)$ & 0.041 & $2.7(2.2-7.9)$ & 0.003 \\
\hline \multicolumn{7}{|l|}{ Missed injuries $(\mathrm{N}=65)$} \\
\hline - Yes & $27(41.5)$ & $38(58.5)$ & 1 & & 1 & \\
\hline - No & $65(76.5)$ & $20(23.5)$ & $4.3(3.1-8.0)$ & 0.012 & $2.9(1.7-9.5)$ & 0.014 \\
\hline \multicolumn{7}{|l|}{ ISS } \\
\hline $\begin{array}{l}-\quad \geq 16 \text { (severe } \\
\text { injury) }\end{array}$ & $72(56.3)$ & $56(43.7)$ & 1 & & 1 & \\
\hline $\begin{array}{l}\text { - } \quad<16 \text { (moderate } \\
\text { injury) }\end{array}$ & 20(90.9) & $2(9.1)$ & $3.8(1.7-6.2)$ & 0.002 & $2.1(1.0-4.9)$ & 0.011 \\
\hline
\end{tabular}

Key: OR = Odds ratio, $\mathrm{Cl}=$ Confidence interval; SBP=systolic blood pressure; ISS= injury severity score

\section{Discussion}

In this study, multiple injuries accounted for one-fifth of all trauma admissions seen during the study period. This concurs with findings of other studies elsewhere (Museru et al., 1998; Museru \& Leshabari, 
2002; Hofman et al., 2005; Chalya et al., 2012), but at variant with other studies (Chalya et al., 2012, 2013) that reported high figures of multiple trauma. These differences in the rate of multiple injuries reflect differences in risk factors for multiple injuries between the study settings. The rate of multiple injuries in our study may be underestimated due to unreported patients, patients who died at scene or who did not reach our hospital because of treatment in other hospitals. A better picture of the magnitude of multiple trauma in our setting requires comprehensive data including police records, hospital admissions, and mortuary records. Better data could support useful policy guidance and help abate this form of trauma and their related morbidity and mortality.

In agreement with other studies (Moini, 2000; Museru \&Leshabari, 2002; Chalya et al., 2010, 2011, 2012, 2013; Chalya \& Gilyoma, 2012), the majority of multiple injury patients were young in their most reproductive and productive years and showed a male preponderance. This group represents the economically active age and portrays an economic loss both to the family and the nation. The reason for their high incidence of trauma reflects their high activity levels and participation in high-risk activities. The fact that the economically productive age-group were mostly involved demands an urgent public policy response. As reported by others (Museru \&Leshabari, 2002; Chalya et al., 2010, 2011, 2012, 2013; Chalya \& Gilyoma, 2012), this study showed that males were more affected than females. The majority of patients in this study came from the rural areas located a considerable distance from the study area. Similar observation was reported by other authors in developing countries (Museru \&Leshabari, 2002; Chalya et al., 2010, 2011, 2012, 2013; Chalya \& Gilyoma., 2012). This observation has an implication on accessibility to health care facilities and awareness of the disease. The presence of pre-existing medical illness has been reported elsewhere to have an effect on the outcome of multiple injured patients (Museru et al., 1998; Krug et al., 2000; Chalya et al., 2010). This is reflected in our study where patients with pre-existing medical illness had significantly high mortality rate.

The prevalence of HIV infection in the present study was $10.7 \%$, a figure that is significantly higher than that in the general population in Tanzania (5.1\%) (Mpondo et al., 2017). However, failure to detect HIV infection during window period and exclusion of some patients from the study may have underestimated the prevalence of HIV infection among these patients. High HIV seroprevalence among multiply injured patients was also reported previously at the same centre by other authors (Chalya et al., 2011; Chalya et al., 2012). The high HIV seroprevalence in our study may be attributed to high percentage of the risk factors for HIV infection reported in the present study population.

The finding that the majority of multiple injuries occurred during the day agrees with that of other studies (Falope, 1991: Museru \& Leshabari, 2002; Chalya et al., 2010, 2011, 2012, 2013; Chalya \& Gilyoma, 2012). Increased rates of injuries during the day can be explained by increased traffic jams as well as increased human activities in the city during the day time. Knowing the time of injury in trauma patient is important for prevention strategies. Most patients in this study sustained blunt multiple injuries, which is comparable with other studies (Falope, 1991; Chalya et al., 2011, 2012, 2013) but in contrast with other studies (Khan, 1999; Solagberu et al., 2002) in which penetrating injuries were most common. The high incidence of blunt injuries in this study can be explained by the fact that the patients were mostly involved in road traffic crash, a common feature of increased motorization in this environment. Road traffic accidents have been reported to be the commonest cause of blunt multiple injuries in a number of studies (Museru \&Leshabari, 2002; Chalya et al., 2010, 2011, 2012, 2013; Chalya \& Gilyoma, 2012). In contrast to our findings, one study reported fall from height as the most common cause of multiple injuries (Falope, 1991). In this study, motorcycles were responsible for the majority of road traffic crashes. The prevalence of motorcycle injuries in this study is higher than that reported two years earlier (Chalya et al., 2012) reflecting an increase in the magnitude of the problem. High incidence of road traffic accidents in our study may be attributed to recklessness and negligence of the driver, poor maintenance of vehicles, driving under the influence of alcohol or drugs and complete disregard of traffic laws. Improvement in 
road conditions, prevention of overloading of commuter vehicles, maintenance of vehicles and encouraging enforcement of traffic laws will decrease the frequency and extent of these injuries.

The prehospital care of trauma patient has been reported to be the most important factor in determining the ultimate outcome after the injury (Chalya et al., 2010, 2011, 2012). Only a few of the patients had pre-hospital care and the majority of them were brought in by relatives, Good Samaritan and police who are not trained on how to take care of these patients during transportation. The majority of patients were brought in by public transport. Similar observation was reported by other studies in Tanzania (Chalya et al., 2010, 2011, 2012). The lack of advanced pre-hospital care in our environment coupled with an ineffective ambulance system are a major challenges in providing care for trauma patients and have contributed significantly to poor outcome of these patients due to delay in definitive management.

In agreement with previous studies (Chalya et al., 2011, 2013), the present study found that musculoskeletal and head injuries were the most common body region injured attributing the latter to the low use of motorcycle helmets in our study; a situation seen in other developing countries (Solagberu et al., 2002). Most of patients in this study sustained soft tissue injuries and long bone fractures. Similar injury patterns were also reported by other authors (Solagberu et al., 2002; Kalemoglu et al., 2006).Good knowledge of the type injury allows the clinicians to plan for the type of surgical treatment and for medico-regal purposes.

The incidence of missed injuries in this study was found to be higher than that reported previously by Chalya et al. (2010) at the same centre. Previous studies have suggested that patients with more severe injuries or associated head injuries tend to have injuries missed during the resuscitation (Enderson \& Maull, 1991; Mitchell et al., 2001; Brooks et al., 2004; Chalya et al., 2010). This is reflected in the high rate of missed injuries in our patients, majority of whom had severe injuries and associated head injuries. The increase in the incidence of missed injuries in patients with severe head injuries suggests that diagnosing injuries improves with better patient communication. Our study confirmed this observation. The high incidence of missed injuries in our study can also be explained by the prospective nature of the study. In this study, missed injuries were found to be associated with prolonged hospital stay, increased need for additional surgery and high mortality rate. This observation concurs with other studies (Enderson \& Maull 1991; Brooks et al., 2004; Chalya et al., 2010). This may be due to the severity of the injuries in this group of patients as evidenced by the higher median injury severity score.

The presence of complications has an impact on the final outcome of patients presenting with multiple injuries as supported by the present study. The pattern of complications in the present study is similar to what was reported by others (Chalya et al., 2010). Early recognition and management of complications in patients with multiple injuries is of paramount in reducing the morbidity and mortality resulting from these injuries. The length of hospital stay has been reported to be an important measure of morbidity among trauma patients (Chalya et al., 2010). Prolonged hospitalization is associated with an unacceptable burden on resources for health and undermines the productive capacity of the population through time lost during hospitalization and disability (Krug et al., 2000). The overall length of hospitalization for both survivors and non-survivors in our study were found to be higher than that reported by other authors (Museru et al., 1998; Moshiro et al., 2005). Prolonged LOS in our study is attributable to presence of major trauma and the large number of patients with long bone fractures which took time to heal as the majority of them were treated with either skeletal or skin traction and only few patients were treated with open reduction and internal fixation. The overall mortality rate in this study was higher than that reported elsewhere (Kalemoglu et al., 2006). Factors responsible for high mortality in our study included associated pre-morbid illness, injury-arrival time, admission systolic blood pressure $\leq 90 \mathrm{mmHg}$, HIV infection with $\mathrm{CD} 4 \leq 200$ cells $/ \mu \mathrm{l}$, ISS $\geq 16$, presence of missed injuries and 
surgical site infection. Addressing these factors responsible for high mortality in our patients is mandatory to be able to reduce mortality associated with these injuries.

Limited study period, failure to detect HIV infection during window period and exclusion of some unconscious patients who had no next of kin to give information regarding the circumstances of the injury were the major limitations in this study and might have underestimated the missed injury rate and HIV seroprevalence in our study. Another limitation was due to the fact that CD4+ cell count was performed in HIV positive patients to determine the degree of immunosuppression despite the fact that CD4 counts are known to be inaccurate in the acute inter-current illness group (Lyamuya et al, 2009). However, despite these limitations, the study has provided local data that can be utilized by health care providers to plan for preventive strategies as well as establishment of management guidelines for patients with multiple injuries.

In conclusion, this study has demonstrated that road traffic accidents remain a major cause of multiple injuries in our setting and contribute significantly to unacceptably high morbidity and mortality. The majority of patients were young adult males in their reproductive age group. Urgent preventive measures targeting at reducing the occurrence of road traffic accidents is necessary to reduce the incidence of multiple injuries in our centre.

\section{Acknowledgements}

The authors thank all those who participated in the preparation of this manuscript, and all those who were involved in the care of our patients. Special thanks go to our research assistants for their help during data collection.

\section{References}

Abubakar, A.S., Ojo, E.O., El-Nafaty, A.U. \& Edomwonyi, N.P. (2008) An audit of one-year intensive care practice in a developing country. Internet Journal of Anesthesiology 18: 2

Bevan, C.A., Babl, F.E., Bolt, P. \& Sharwood, L.N. (2008) The increasing problem of motorcycle in Children and Adolescents. Medical Journal of Australia 189: 17-20.

Brooks. A., Holroyd, B. \& Riley, B. (2004) Missed injuries in major trauma patients. International Journal of Care of Injured 35: 407-410.

Buduhan, G.M. \& Donna, I. (2000) Missed injuries in patients with multiple trauma. Journal of Trauma 49: 600-605.

Chalya, P.L., Mabula, J.B., Ngayomela, I.H., Kanumba, E.S., Chandika, A.B., Giiti, G., Mawala B. \& Balumuka, D.D. (2010) Motorcycle injuries as an emerging public health problem in Mwanza City, north-western Tanzania. Tanzania Journal of Health Research 12: 214-221

Chalya, P.L., Mabula, J.B., Dass, R.M., Nkinda, M., Ngayomela, I.H., Chandika, A.B. \& Gilyoma, J.M. (2012) Injury characteristics and outcome of road traffic crash victims at Bugando Medical Centre in Northwestern Tanzania. Journal of Trauma Management \& Outcomes 6:1.

Chalya, P.L., Gilyoma, J.M., Dass, R.M., Mchembe, M.D., Matasha, M., Mabula, J.B., Nkinda, M. \& Mahalu, W. (2011) Trauma admissions to the Intensive care unit at a reference hospital in Northwestern Tanzania. Scandinavian Journal of Trauma, Resuscitation and Emergency Medicine 19: 61.

Chalya, P.L. \& Gilyoma, J.M. (2012) The burden of intentional injuries in Mwanza City, north-western Tanzania: a tertiary hospital survey. Tanzania Journal of Health Research 14: 204-211.

Chalya, P.L., Mchembe, M., Gilyoma, J.M., Mabula, J.B., Ngayomela, I.H., Chandika, A.B. \& Mawala, B. (2010) Missed injuries in multiple trauma patients: A tertiary care experience in Tanzania. East and Central African Journal of Surgery 15: 39-46. 
Chalya, P.L., Dass, R.M., Mchembe, D.M., Mbelenge, N., Ngayomela, I.H., Chandika, A.B., Gilyoma, J.M. \& Mabula, J.B. (2013) Citywide trauma experience in Mwanza, Tanzania: a need for urgent intervention. Journal of Trauma Management \& Outcomes 7:9.

Chalya, P.L., Mabula, J.B., Giiti, G., Chandika, A.B., Dass, R.M., Mchembe, M.D. \&, Gilyoma J.M. (2012) Splenic injuries at Bugando Medical Centre in north-western Tanzania: a tertiary hospital experience. BMC Research Notes 5:59.

Chawda, M.N., Hildebrand, F., Pape, H.C. \& Giannoudis, P.V. (2004) Predicting outcome after multiple trauma: Which scoring system? Injury 35: 47-58.

Duane, T.M., Rao, R.I., Aboutanous, M.B., Wolfe, L.G. \& Malhotra, A.K. (2008) Are trauma patients better off in a trauma ICU? Journal of Emergency Trauma and Shock 1: 74-7.

Enderson, B.L. \& Maull, K.I. (1991) Missed injuries: The trauma surgeon's nemesis. Surgical Clinic of North America 71: 399-417.

Falope, I.A. (1991) Motorcycle accidents in Nigeria a new group at risk. West African Journal of Medicine 10: 187-189.

Hofman, K., Primack, A., Keusch, G. \& Hrynkow, S. (2005) Addressing the growing burden of trauma and injury in low- and middle-income countries. American Journal of Public Health 95: 13-17.

Kalemoglu, M., Demirbas, S., Akin, M.L., Yildirim, I., Kurt, Y., Uluutku, H. \& Yildiz, M. (2006) Missed injuries in military patients with major trauma. Military Medical Journal 17: 598-602.

Khan, A. (1999) Stab wounds abdomen: an experience with 105 laparotomies. Journal of Ayub Medical Collage of Abbottabad 11: 6-8.

Krug, E.G., Sharma, G.K. \& Lozano, R. (2000) The global burden of injuries. American Journal of Public Health 90: 523-526.

Lyamuya, E.F., Aboud, S., Urassa, W.K., Sufi, J., Mbwana, J., Ndungulile, F. \& Massambu, C. (2009) Evaluation of rapid HIV assays and development of national rapid HIV test algorithms in Dar es Salaam, Tanzania. BMC Infectious Diseases 9: 19.

Mitchell, V.T., Scarlett, M.D. \& Amata, A.V. (2001) Trauma Admissions to the ICU of the University Hospital of the West Indies, Kingston, Jamaica. Trauma Care Fall/Winter 86-89pp.

Moini, M., Rezaishiraz, H. \& Zafarghandi, M.R. (2000) Characteristics and outcome of injured patients treated in urban trauma centers in Iran. Journal of Trauma 48: 503-7.

Moshiro, C., Ivar, H., Anne, N., Philip, S., Yusuf, H. \& Gunnar, K. (2005) Injury morbidity in an urban and a rural area in Tanzania: an epidemiological survey BMC Public Health 5: 11.

Mpondo, B.C.T., Gunda D.W., \& Semvua, B. \& Kilonzo, S.B. (2017) HIV Epidemic in Tanzania: The Possible Role of the Key Populations. AIDS Research and Treatment Volume 2017, Article ID 7089150, 7 pages. https://doi.org/10.1155/2017/7089150

Museru, L.M. \& Leshabari, M.T. (2002) Road traffic Accidents in Tanzania: A 10-year epidemiological appraisal. East and Central African Journal of Surgery 7: 23-26.

Museru, L.M., Leshabari, M.T., Grob, U. \& Lisokotola, L.N.M. (1998) The pattern of injuries seen in patients in the orthopedic/trauma wards of Muhimbili Medical Centre. East and Central African Journal of Surgery 4: 15-21.

Park, K. (2000) Accidents. In: Textbook of Social and Preventive Medicine. 17 edition. Edited by: Park K. Jabalpur: Banarsidas Co; 304-5.

Sandra, M., Salvador, N., Pere, R., Judit, M.H. \& Gabriel, C. (2008) A prospective study on the incidence of missed injuries in trauma patients. Cir Esp. 84, 32-6

Solagberu, B.A., Adekanye, A.O., Ofoegbu, C.P.K., Kuranga, S.A., Udoffa, U.S., Abdur-Rahman, L.O., Odelowo, E.O.O. (2002) Clinical spectrum of trauma at a university hospital in Nigeria. European Journal of Trauma 28: 365-369. 
Shirzard, H., Morlen, S.L., Carsten, H. (2002) Missed injuries in a Level 1 Trauma Centre. Journal of Trauma 52: 715-719. 